\title{
THE ANATOMICAL RECORD.
}

No. $\%$.

November $10,190 \%$.

EFFECTS OF EARIY REMOVAL OF THE HEART AND ARREST OF THE CIRCULATION ON THE DEVELOPMENT OF FROG EMBRYOS. ${ }^{1}$

BY

H. McE. KNOWER.

The Anatomical Laboratory, Johns Hopkins University.

This study was first undertaken to test the action of solutions of acetone-chloroform, a specific heart poison, in suppressing the circulation from the earliest possible stage of frog embryos, especially with eggs of R. Palustris and R. Sylvatica. Loeb made some similar experiments in 1893 with solutions of potassium chloride ( $\mathrm{KCl}$ ) acting on the eggs of a fish (Fundulus), but based bis conclusions on living embryos only, without comparing them with preserved material and sections.

In order to eliminate any possible direct action of a drug on cells other than those of the heart, and yet to examine the effects of an arrest of the circulation on the development of other structures, it seemed best to simply cut out and remove the heart rudıment at a stage as early as possible. Cuts were made so as to carry the heart rudiment away in a wedge-shaped piece, injuring neighboring structures as little as possible. The embryo was now placed in 0.2 per cent sodium chloride solution in tap water for a few days, and then into plain tap water, in which development continued for as long as fourteen days. The method of operating was varied, in efforts to limit the amount of tissues taken away, or to insure complete removal of the heart and the large vessels immediately attached.

The development of embryos operated upon in this way proceeds actively, the wound closing in the first day, where the cuts have not exposed too great a surface of yolk. By the fourth day the abnormal

${ }^{1}$ This paper was presented to the Seventh International Zoological Congress, before the section of Embryology and Experimental Zoology. Boston, Mass., August 22, $190 \%$.

The ANatomical Recond,-No. 7. 
(6 $\mathrm{mm}$. to $7 \mathrm{~mm}$.) are readily distinguished from the normal $(7 \mathrm{~mm}$. to $8 \mathrm{~mm}$.) larvæ, both by size and form.

On the fifth day $(8-9 \mathrm{~mm}$.) it is possible to observe the pulsations of the anterior lymph hearts, at an earlier stage and more clearly than by any other method. Often the lymph hearts may be identified earlier; but from this stage the increasing œdema distends the skin and spreads the connective tissue and pigment cells apart, until the attachments to surrounding cells, the action of the valves, and the course of blood corpuscles can be studied with ease. Indeed this is the best method of demonstrating the embryonic lymph hearts and the pronephros, as I pointed out in 1903. Fluid now continues to accumulate in the cavities of the body which soon become swollen, while the walls become transparent. The internal organs are then seen with exceptional clearness in living specimens or in cedar oil.

By the tenth day the larva has assumed a most abnormal form, due to the œdema. In extreme cases, the distension of the abdomen is so great as to give the appearance of a fish embryo lying on its yolk sac; while from above the swellings of the pronephric and head sinuses make a very odd picture. These specimens move around awkwardly. They do not seem to grow much or differentiate after the ninth day, and are now on the tenth day, hardly half as large as their controls.

Between the tenth and thirteenth days the tail usually begins to shrivel, and the abdominal walls are apt to burst from excessive œdema. In any event the operated larvæ die about this time.

A study of operated larva, in sections and as entire specimens in cedar oil, helps us to form a more accurate idea of the effects of the arrest of the circulation on the development of regions not immediately injured by the operation. In the first place two periods in the development of these embryos are plainly emphasized. The earlier stages, up to about the fifth day, are occupied with the primary differentiation of tissues and organs, in the typical manner. After this, though the embryo may continue to live for more than twice this period, further differentiation is arrested. Increase in size (or growth) is now due, in part only to the multiplication of cells, mostly to the great distension of cavities and spaces from the cedema. There appear to be fewer cells in the older operated specimens than in normal ones of the same age. The period of primary differentiation and establishment of the typical forms of organs is not followed by the usual further elaboration of relations characteristic of older larvæ.

The arrest in the development of organs may be observed most readily 
in unstained and partially dissected specimens studied in cedar oil. The digestive tract exhibits one of the most striking abnormalities. It is limited to a single coil. It represents the intestine of about the stage of a normal four day embryo. The liver and pancreas are arrested, if present. Injury to the early rudiments persists, their being no regeneration.

The mesentery becomes much distorted; being transformed into a great bag, in which many corpuscles accumulate, and into which the aorta generally opens freely. The pronephric sinus may also open into the mesentery, and fluid or corpuscles propelled through the anterior lymph hearts soon reach this great sac.

When these larvæ are viewed from above and compared with the normal of the same age in cedar oil, the central nervous system of operated specimens is seen to be much smaller, while the subdivisions of the brain have failed to acquire their specific size and shape. This is most evident in the forebrain, where the vesicles open widely backward and have not enlarged normally. The eyes cling abnormally close to the brain. They are less than one-half as large as normal, and in ten days, hardly developed beyond normal five day eyes. (This is especially well shown by the lens). The walls of the optic cup cling closely around the little rudimentary lens, leaving almost no cavity within. The ear vesicles are less than one-half the normal size.

The musculature is underdeveloped, and after five or six days much vacuolated. The connective tissue develops normally during the first four days, until the cedema begins to be extensive. After this the cells do not multiply so vigorously, nor do they form a characteristic network. Fluid accumulates so freely between them as to stretch their processes and give the whole an attenuated appearance in place of the rather dense mesh of the usual ten day embryo.

The posterior cardinal vein on each side, and the sinus communicating with it and surrounding the pronephric tubules have become so greatly distended in these stages that the outer wall of the pronephros covers about one-third of the side of the embryo. A spacious chamber is formed in which the tubules occupy a novel position, the nephrostimal tubules being much enlarged and stretched outward to the collecting ducts and reservoir, which lie dorsally and near the outer surface. The whole system is thus readily studied in total mounts. The common duct exhibits only a few simple bends, as it runs back through the great sinuslike vein. The lumina of the tubules are enlarged, the cells vacuolated and irregular. The glomernlus is usually transformed into a hardly 
recognizable sinus. Though much distorted, the pronephros finally reaches a stage which may be compared to that of a normal embryo between four and five days.

In examining the tails of a series of these larvæ the normal character of the early stages of outgrowth is striking. The tail appears to pass through the typical changes, except in larvæ which have suffered excessive injuries anteriorly, in which case the tail fin is decidedly less expanded and shrivels early. The musculature has been described above. The connective tissue cells are relatively few, more scattered, and less organized than in a five day normal embryo.

The effect of these experiments on the development of the vascular system is interesting. The heart does not regenerate; (nor do other structures whose rudiments have been removed in these operations). Remnants of its chambers developing from uninjured portions of the rudiment, beat rythmically. Even after most extensive operation, involving much of the neighboring tissues, before the heart is clearly differentiated, the aorta the large veins and the segmental vessels are laid down. It has not been possible to inhibit their formation, which therefore apparently takes place in situ. The anterior lymph hearts are constantly formed, though distorted. Both arteries and veins are very abnormal and have a few well defined smaller branches. All vessels become much distended, and follow very irregular courses. The aorta and pronephric sinuses open into the mesentery. The glomeruli are dilated sacs. A study of the tail shows that the aorta and veins are there also much distended. In most cases the first pre-capillary loops are represented by enlarged sinuses, but there is a notable absence of capillaries in the fin. These smaller vessels do not push out nor form characteristic plexuses. Their development is inhibited. The weaker the heart beat, in fact, the less does the blood flow outward from the larger vessels and pre-capillary loops. Corpuscles are relatively few, and collected mostly in the mesentric bag; also in the aorta, post cardinal veins, pronephric sinuses, and the anterior lymph hearts.

There is no circulation through the gills after successful operations, and the gills fail to develop beyond rudimentary buds. There cannot be said to be a definite circulation in a true sense, where the systemic heart has been eliminated; though it is true that the corpuscles and fluids are kept moving through some of the larger vessels and the mesenteric sac, by the pulsations of the anterior lymph hearts. Even when a remnant of the heart beats, there is this imperfection.

Attention should be here called to the similarity between these larvæ 
and those with weak circulation produced from eggs developed in certain poisons, or after exposure to the X-rays. Late in the season abnormal bunches of eggs are often found, many of which develop into similar arrested and distended larvæ with weak circulation.

On the whole it would be difficult to find a better example, to illustrate the influence of a complete and efficiently functioning vascular system on the later elaboration of structure and form. The primary formative forces are well exhibited here, acting in the earlier stages to establish the characteristic tissues and organs and arrangement of the entire body structure; but, with this, the impetus to continued differentiation becomes limited, and in the absence of elaborate special capillary systems further development is arrested and growth rendered abnormal. In tadpoles this remains true, in spite of the extra provision of the cells with yolk, and the activity of the anterior lym.ph hearts.

The Afatomical Rhcond.-No. 7. 